\title{
Derecha y agronegocio en Argentina y Brasil. Cambios y continuidades
}

\author{
Right and agribusiness in Argentina and Brazil. \\ Changes and continuities
}

\author{
María Eugenia Isidro \\ Universidad Nacional de Río Cuarto \\ mariaeugeniaisidro@gmail.com \\ Código Orcid: https://orcid.org/0000-0002-0954-2645 \\ Nicolás Forlani \\ Universidad Nacional de Río Cuarto \\ forlani.nicolas@gmail.com \\ Código Orcid: https://orcid.org/0000-0002-3890-4967
}

\begin{abstract}
Resumen
Una de las modalidades de acumulación por despojo más expandidas en Sudamérica la constituye el avance del agronegocio. Esta lógica neoextractivista se ha expandido en Argentina y Brasil aun en el marco de las alternancias políticas que ambos países han experimentado en los últimos años. Sin embargo, es posible advertir contrastes en relación a las políticas gubernamentales para el sector agrario según el signo político al que se aluda: gobiernos posneoliberales versus ascenso de las derechas. De allí que el objetivo del presente trabajo sea el de caracterizar a las derechas actuales en ambos países en lo que hace a la dinámica del agronegocio tendiendo a una comparación con lo que fueron las políticas implementadas durante los gobiernos progresistas. Para tal cometido acudimos a un abordaje metodológico de tipo cualitativo basado en la revisión bibliográfica especializada en el tema y el análisis de documentos. Entre los principales resultados se advierte que si bien existe una matriz consolidada del agronegocio en ambos países (y que como tal la misma se conserva aún en el marco de la alternancia política); esta lógica hegemónica de producción empero se profundiza con la llegada al Gobierno de Macri (Argentina 2015) y Temer (Brasil 2016). Con estos gobiernos áreas estatales de apoyo a la agricultura campesina son desmanteladas al tiempo que se estimula la producción de commodities y el acaparamiento de tierras por grandes propietarios.
\end{abstract}

\section{Palabras clave}

Derecha, agronegocio, Argentina, Brasil, políticas públicas, desigualdad.

Forma sugerida de citar: Isidro, M., y Forlani, N. (2019). Derecha y agronegocio en Argentina y Brasil. Cambios y continuidades. Universitas, 31, pp. 59-77. 


\begin{abstract}
One of the most expanded forms of accumulation by dispossession in South America is the advancement of agribusiness. This neoextractivist logic has expanded in Argentina and Brazil even in the framework of the political alternations that both countries have experienced in recent years. However, it is possible to notice contrasts in relation to government policies for the agrarian sector according to the political sign that is alluded to: post-neoliberal governments versus the rise of the rights. Hence, the objective of this paper is to characterize the current rights in both countries in what makes the dynamics of agribusiness tending to a comparison with what were the policies implemented during the progressive governments. For such a purpose we resort to a methodological approach of qualitative type based on the bibliographic review specialized in the subject and the analysis of documents.

Among the main results, it is noted that although there is a consolidated agribusiness matrix in both countries (and as such it is still preserved in the framework of political alternation); This hegemonic logic of production, however, is deepened with the arrival in the government of Macri (Argentina 2015) and Temer (Brazil 2016). With these governments, state support areas for peasant agriculture are dismantled while stimulating the production of commodities and land grabbing by large landowners.
\end{abstract}

Keywords

Right, agribusiness, Argentina, Brazil, public policies, inequality.

\title{
Introducción
}

El neoextractivismo se presenta como un sistema estructuralmente anclado en los territorios latinoamericanos. Se trata de un mecanismo de acumulación por desposesión (Harvey, 2005) que posee una extensa trayectoria de explotación de cuerpos y territorios, es decir se inscribe como un fenómeno de larga duración, siempre en detrimento de las amplias mayorías sociales y la de los bienes naturales. En este sentido, cuando hablamos de neoextractivismo nos referimos a un sistema de producción caracterizado por la utilización de técnicas de exploración y explotación del medio ambiente que han ido transformando de manera progresiva los bienes naturales renovables básicos para la vida en bienes potencialmente no renovables, al mismo tiempo que los convierte en commodities (Composto \& Navarro, 2014). 
En el marco del neoextractivismo, el agronegocio se inscribe como una lógica que caracteriza la producción agraria de países latinoamericanos, entre los que se encuentran Argentina y Brasil. Pensar el neoextractivismo y, en particular, el agronegocio en clave política requiere partir de una interpretación respecto a las fuerzas políticas que gobiernan ambos países. Una oleada neoliberal parece signar la actual coyuntura latinoamericana arrastrada por el triunfo electoral o la imposición de fuerzas políticas ubicadas a la derecha del espectro político.

La referencia en tal sentido a la noción de "derecha" como clave descriptiva, clasificatoria e interpretativa de varios de los gobiernos latinoamericanos, no está exenta de debates en la academia en torno a si estamos ante fuerzas de derecha cuyas formas y contenidos son presuntamente novedosos (Giordano, 2014; Natanson, 2017; López Segrera, 2016), o si más bien asistimos a experiencias políticas que, más allá del aggiornamiento estético/ discursivo, no se diferencian en lo esencial del auténtico pensamiento de derecha (Ansaldi, 2017; García Linera, 2016; Sader, 2015).

En este marco, el presente trabajo busca caracterizar estas fuerzas que hoy gobiernan en países como Argentina y Brasil prestando principal atención a sus políticas vinculadas al neoextractivismo, centrándonos especialmente en la matriz del agronegocio. Este sistema productivo trae aparejados los procesos de acaparamiento de tierras, expansión de fronteras agropecuarias, cambios en el uso del suelo impulsados por los llamados "commodity booms" y en los sistemas productivos y tecnológicos (Gras \& Hernández, 2013). Al mismo tiempo, en muchos casos, genera resistencias colectivas por parte de las poblaciones que se oponen al modelo.

Dado el carácter complejo de la temática de estudio apelamos a un abordaje multidisciplinario que favoreció, a partir del aporte de la ciencia política, la sociología y la economía, un abordaje amplio del tema en cuestión.

Para la realización de este trabajo acudimos a una metodología de tipo cualitativa en donde analizamos, de manera interpretativa, información proveniente de diferentes fuentes como documentos oficiales, notas periodísticas e informes que nos permitan abordar el objeto de interés desde una mirada amplia. Esto nos posibilitará divisar cambios y continuidades a nivel de políticas públicas y marcos normativos vinculados al agronegocio tanto en Argentina como en Brasil. 
Es importante aclarar que este trabajo retoma parte de lo expuesto en la $8^{\circ}$ Conferencia Latinoamericana y Caribeña de Ciencias Sociales (CLACSO) ${ }^{1}$ instancia en la cual además presentamos las implicancias que estos cambios acaecidos en torno al agronegocio generan en los movimientos sociales contestatarios al modelo hegemónico de producción agropecuario.

\section{De gobiernos y lógicas de producción}

\section{Las derechas latinoamericanas}

Los virajes políticos de la América del Sur reciente grafican, parafraseando a Álvaro García Linera (2016), el desarrollo de oleadas progresistas y conservadoras que ha atravesado la región. Tras una primera década del siglo en curso marcada por gobiernos con signos mayoritariamente posneoliberales, las sociedades sudamericanas actuales se hallan gobernadas ampliamente por expresiones de derecha.

Aun concibiendo que los calificativos "izquierda" y "derecha" no deben ser interpretados en ausencia de una mirada analítica en clave relacional, máxime cuando se trate de comparar posicionamientos políticos y, en términos generales, políticas públicas, compartimos que es posible distinguir "a priori” peculiaridades inherentes a cada expresión política. Dicho en otros términos, si bien izquierda y derecha se definen en el plano de la alteridad ("a la izquierda de" / "a la derecha de"), habría fundamentos "per se" que caracterizan a toda fuerza de derecha vis a vis de izquierda.

Coincidimos con Bobbio (1995) al plantear que es el binomio igualdad / desigualdad lo que permite distinguir a las fuerzas políticas. Mientras que quienes bregan por mayor igualdad (no nos circunscribimos solamente a la órbita económica) lo son las fuerzas de izquierda, las derechas en cambio optan "por el mantenimiento de la desigualdad" (Ansaldi, 2017, p. 31).

Mientras el debate respecto al modo de caracterizar a las fuerzas políticas gobernantes de inicio de siglo no logró ser saldado (posneoliberales, progresistas, de izquierda, etc.), nuevas discusiones suscitan los gobiernos en curso en torno a si efectivamente son nuevas derechas o, en cambio, no

1 El trabajo se tituló "El agronegocio tras el viraje hacia la derecha en Argentina y Brasil”. Este trabajo tenía como principal objetivo establecer las implicancias que las políticas en torno a la actividad agropecuaria desencadenaban con relación a los movimientos sociales contestatarios al agronegocio. 
se distinguen de las derechas de antaño (Quiroga \& Juncos Castillo, 2018). Incluso más, el derrotero político regional reciente pareciera volver ya añejo el debate por las derechas actuales para abrir paso a discusiones en torno al viraje hacia extremas derechas.

En el presente trabajo nos centraremos en dos expresiones de derecha, la de los dos países de mayor peso relativo en Sudamérica, nos referimos a los casos de Brasil bajo el Gobierno de Michel Temer tras la destitución de Dilma Rousseff en agosto de 2016 y la posterior asunción de Jair Bolsonaro en 2019 así como el de la Argentina tras la llegada de Mauricio Macri al Ejecutivo Nacional hacia fines del año 2015. La propuesta de indagar sobre las políticas de ambos gobiernos respecto a la matriz productiva agropecuaria supone un peculiar desafío en tanto la caracterización de ambos gobiernos sobre esta área no podrá realizarse sin contemplar las políticas de los anteriores gobiernos a los fines de advertir, desde un ejercicio analítico comparativo, la existencia o no de contrastes.

\section{El agronegocio, modelo productivo imperante}

En la actual etapa del desarrollo del capitalismo neoliberal su naturaleza predatoria sobre los países subdesarrollados se encuentra exacerbada ${ }^{2}$. Grandes empresas dominan sectores claves de la producción y comercialización, así como las tecnologías de última generación utilizadas. La acumulación se explica por la exportación de la naturaleza y la privatización de bienes naturales comunes. Se trata de una organización de la economía basada en la dependencia de la extracción intensiva de bienes naturales, con muy bajo valor agregado, destinados a la exportación a gran escala y cuyo precio se fija internacionalmente.

Si nos centramos en el modelo de producción agrícola es posible registrar, a partir de la década de 1990, cambios que implican profundas transformaciones en los actores involucrados y en los procesos de organización, otorgándole mayor centralidad al capital financiero y posicionando a la actividad esencialmente como negocio lo que habilita la acción económica en un horizonte casi ilimitado (Gras \& Hernández, 2013).

2 Sobre el carácter predatorio y exacerbado del capitalismo en tiempos del neoliberalismo ver Borón (2004) "Hegemonía e imperialismo en el sistema internacional". Disponible en: https://bit.ly/2YhEii0 
Desde la perspectiva de Gras y Hernández (2013) el agronegocio se sostiene sobre cuatro pilares fundamentales: el tecnológico, el financiero, el productivo y el organizacional. La implementación de nuevas tecnologías (biotecnológicas, de información y comunicación) utilizadas en la producción agropecuaria transformaron los sistemas productivos agropecuarios, llegando a ser en la actualidad la región latinoamericana la de mayor extensión en cultivos transgénicos en el mundo, siendo la soja el principal cultivo. Producir bajo este sistema lleva a una dependencia asimétrica de actores globales quienes determinan las innovaciones que comprenden el sistema de siembra directa, las semillas transgénicas, los agroquímicos, las maquinarias y equipos, la organización laboral y la gestión empresarial.

La participación del capital financiero en la actividad agropecuaria tiene lugar a través de créditos, financiamientos ofrecidos por los bancos, cobertura de riesgos climáticos o de variaciones de precios a futuro y fondos de inversión. Toda esta actividad financiera fue creciendo con los años a partir de la liberación del marco regulatorio y el aumento de los volúmenes de producción a partir de los años 90. Posteriormente, también creció a consecuencia del aumento de los precios internacionales de los commodities. A través de estas herramientas el capital financiero especula e influye en la fijación de precios y en las rentabilidades del sector en cada uno de los países de la región, buscando prioritariamente ganancias en corto plazo.

Con respecto a lo productivo, el agronegocio genera cambios tanto en la tierra como en el trabajo. El fenómeno de la concentración de la tierra se ha profundizado en las últimas décadas debido a que la mayor eficiencia del sistema productivo se alcanza a partir de grandes escalas, a la consideración de que la tierra es un recurso finito y a la participación del capital financiero en la valorización de este activo.

Por su parte, el trabajo vinculado al agronegocio ha sufrido transformaciones en dos sentidos. Por un lado, la tercerización de algunas labores a partir de la expansión del contratismo. Por otro lado, cada etapa del proceso productivo fue asumida por un actor económico diferente estableciéndose una red en el negocio agrícola. Se encuentran en una punta los gerenciadores de la red, cuya noción de trabajo se basa en prácticas cognitivo-intelectuales que requieren de una formación especializada obtenida dentro del sistema educativo formal. En el medio están los responsables de las empresas que prestan servicios, los propietarios o arrendatarios de las tierras y los financistas. En el otro extremo 
de la red se encuentran los que realizan el trabajo físico en las tareas agrícolas como el tractorista, el fumigador, el maquinista de la cosechadora, etc.

En lo que refiere a lo organizacional se ha pasado de la lógica del negocio de propiedad familiar, al territorio y la economía global que requieren de otras escalas y conocimientos. La gestión familiar dio lugar al management moderno en donde el empresario se mueve en función de las necesidades cambiantes del sistema y estimulados por el marketing, que permite una recomposición permanente de su organización en virtud de los contextos y oportunidades del negocio. En definitiva, se requiere del conocimiento y de una amplia gama de competencias relacionadas a la economía global, las nuevas tecnologías de la información, comunicación y biotecnología, etc.

El desarrollo de cada uno de estos pilares significó la consolidación del agronegocio como sistema de producción imperante en el sur latinoamericano. Asimismo, para el fortalecimiento de esta lógica productiva fue fundamental el despliegue de una activa construcción de legitimidad respecto de los beneficios del agronegocio en tanto modelo productivo. Tanto en Brasil como en Argentina es posible divisar instituciones que operaron en ese sentido, tal es el ejemplo de entidades como la Asociación Argentina de Productores en Siembra Directa (AAPRESID) y la Asociación Argentina de Consorcios Regionales de Experimentación Agrícola (AACREA) en Argentina y, en Brasil, la Associação Brasileira do Agronegócio (ABAG) y la Federação Brasileira de Plantio Direto e Irrigação (FEBRAPDP).

\section{Agronegocio en Argentina y Brasil}

La expresión "República Unida de la Soja" popularizada en una publicidad de la transnacional Syngenta ilustra la realidad del Cono Sur latinoamericano y saca a relucir una característica del agronegocio: no tiene fronteras. Esta "República" imaginaria está conformada por Argentina, Brasil, Paraguay, Uruguay y Bolivia.

Hacia el 2013, esta región abarcaba una superficie de más de 46 millones de hectáreas de monocultivo de soja transgénica, fumigadas con más de 600 millones de litros de glifosato, este proceso implica la deforestación de 500 mil hectáreas por año, como mínimo. ${ }^{3}$

3 Fuente: "La República Unida de la Soja recargada", informe elaborado por GRAIN (2013) Disponible en: https://bit.ly/2OwN7Aa 
Argentina, junto a Estados Unidos y Brasil, son los tres países con mayor producción de soja a nivel mundial, la misma ronda el $80 \%$. Un informe elaborado por el Instituto Nacional Tecnología Agropecuaria (INTA) ${ }^{4}$ en 2016 sostiene que la soja es el principal cultivo de la Argentina no sólo por la producción, sino por la superficie ocupada. Por entonces, representaba el 55\% de los casi 37 millones de hectáreas que se siembran, seguida muy de lejos por los cultivos de maíz y trigo que, en conjunto, representaban el $26 \%$, es decir menos de la mitad. En Brasil, por su parte, la superficie agrícola acaparada por esta oleaginosa ocupa el $36,72 \%$ mientras que la caña de azúcar (otro de los cultivos representativos del agronegocio brasileño) alcanza el 13,41\% (Guereña, 2016).

Ambos países, por otra parte, registran elevados índices de desigualdad con relación a la propiedad de la tierra. Según el informe de la organización OXFAM (Guereña, 2016), el coeficiente Gini marca para la Argentina 0,83 y para Brasil 0,87. Las grandes extensiones agrícolas en manos de pocos propietarios que se registra en estos dos países se enmarca en un marco subcontinental regido por patrones similares. ${ }^{5}$

Si bien la región ha experimentado a lo largo de su historia un proceso de acaparamiento de tierra o land grabbing, es durante la primera década del siglo XXI, más precisamente a partir de la debacle financiera del 2008, que este proceso se acelera dado que los capitales financieros encuentran en la tierra un ámbito propicio para la reproducción del capital (Frederico \& Gras, 2017). La particularidad de este fenómeno está dada en que, en el Cono Sur latinoamericano, se destaca el papel desempeñado por megaempresas de origen argentino como puerta de entrada del capital especulativo internacional a la región.

\section{Agronegocio en Argentina. Desde Néstor Kirchner a Mauricio Macri}

Si bien en la década de 1970 se inicia un proceso de expansión de la producción de soja a raíz de la preferencia de este producto agropecuario en

4 Fuente: "Informe estadístico mercado de la soja", informe elaborado por el INTA. Disponible en: https://bit.ly/2LTg3jF (10/02/2018).

5 Según el informe mencionado el $1 \%$ de las fincas de mayor tamaño concentran en América Latina más de la mitad de la superficie agrícola. "Dicho de otro modo, el $1 \%$ de las fincas acapara más tierra que el 99\% restante" (Guereña, 2016, p. 23). 
detrimento de otros (Giarraca \& Teubal, 2013), es a mediados de los años 90 cuando el agronegocio comienza a consolidarse en Argentina al liberase al mercado la soja transgénica. Este cambio en la producción agropecuaria incluye la implementación de un nuevo paquete tecnológico basado en la siembra directa y el uso masivo e intensivo de agroquímicos provocando, al mismo tiempo, la expansión de la frontera agraria y un fuerte impacto socio ambiental - acaparamiento de tierras, pérdida de bosques nativos, entre otros - (Gras \& Hernández, 2013). De esta manera se abre paso a la consolidación del agronegocio en Argentina, sistema que además propicia el control de sectores clave del sistema agroalimentario argentino por parte de grandes empresas transnacionales. Importa resaltar que la incorporacrión de estas nuevas tecnologías se produce, al decir de Basualdo et al. (2013), prácticamente en una misma temporalidad que en países desarrollados, lo cual convierte a Argentina en pionera en lo que refiere a la adopción del paquete tecnológico del agronegocio.

En la Pampa Húmeda es donde se concentra la mayor producción de soja en Argentina. Esta región incluye las provincias de Santa Fe, Córdoba, Buenos Aires y La Pampa. Maldonado (2013) plantea una serie de características de esta región: concentración de la explotación económica del suelo; ampliación de la frontera agraria mediante procesos de desmonte; pérdida de diversidad productiva; aplicación de paquetes tecnológicos provistos por empresas transnacionales que involucran siembra directa, semillas transgénicas y paquetes de agroquímicos asociados; creciente protagonismo de figuras del orden financiero de asociación en el sector y disminución de la población económicamente activa rural.

Resulta importante asentar que las transformaciones propulsadas en la década del 90 en materia agropecuaria no solo se han mantenido sino incluso profundizado es que, al compás de la aprobación de diversas semillas modificadas genéticamente, año a año, la producción de transgénicos se intensificó en el área pampeana expandiéndose incluso hacia áreas extrapampeanas.

El dato no resulta irrelevante máxime cuando es posible constatar la alternancia político-ideológica experimentada en el país entre un primer período con signos neoliberales (gobiernos de Carlos Menem y de Fernando de la Rúa) y un proceso político de características posneoliberales como el desarrollado durante el Kirchnerismo (gobiernos de Néstor Kirchner y Cristina Fernández). Es decir, aun con sus diferencias económicas (basado el primero en un régimen de valorización financiera en contraste con la apues- 
ta mercado internista del segundo) y geopolíticas (relaciones bilaterales con los Estados Unidos durante el menemismo y la búsqueda de la integración sudamericana bajo el kirchnerismo) la lógica del agronegocio no solo permaneció sino incluso se profundizó. De allí que coincidamos con Martínez Dougnac (2013) en torno a que:

A pesar del signo novedoso de algunas de las políticas oficiales (...) se mantendría lo esencial de las reformas estructurales llevadas a cabo por el presidente Menem. Esta continuidad resulta particularmente evidente en el sector agrario, donde buena parte de las tendencias heredadas no solo persisten, sino que se potencian y fortalecen: agriculturización, sojización, concentración económica, predominio de economías de escala (...). (Martínez Dougnac, 2013, p. 334)

En este sentido, como sostiene la autora, en el contexto de la posconvertibilidad se profundizaron los rasgos del modelo agrario dominante. Es que, con una estructura de costos relativamente bajos fruto de la recesión tras el agotamiento del régimen neoliberal, en un contexto internacional en alza de los commodities y de un elevado tipo de cambio a raíz de la fuerte devaluación de la moneda nacional (del régimen de convertibilidad el tipo de cambio se devaluó en una relación de 4 pesos 1 dólar), la producción agrícola centrada en la demanda externa encontró el escenario propicio para su expansión.

Sin embargo, la continuidad estructural respecto a la lógica agropecuaria del agronegocio, enmarcada en patrones globales de acumulación, no debe opacar políticas públicas implementadas durante los gobiernos kirchneristas que habilitaron la emergencia de ciertas contradicciones (o al menos tensiones) al interior de la hegemonía del "agro como negocio". Es decir, decisiones gubernamentales que, sin alterar la expansión de una lógica productiva basada en el paquete tecnológico de los transgénicos, habilitaron interpretaciones respecto a concebir al Estado en los términos en que Samir Amin (2005) lo interpretase, esto es el Estado no solo como el estado del capital sino también como el resultado de la disputa entre el capital y la sociedad.

A propósito de ello es factible identificar al menos cuatro disposiciones legislativas cuyos alcances materiales si bien fueron variantes no dejan de significar, al menos desde lo simbólico, decisiones controvertidas para las lógicas del capital asociadas al agronegocio:

Ley de protección ambiental del bosque nativo (Ley 26.331): esta ley promulgada en 2007 establece los presupuestos mínimos de protección am- 
biental para el enriquecimiento, la restauración, conservación, aprovechamiento y manejo sostenible de los bosques nativos y de los servicios ambientales que éstos brindan a la sociedad. Asimismo, establece un régimen de fomento y criterios para la distribución de fondos por los servicios ambientales que brindan los bosques nativos.

El Régimen de Trabajo Agrario (Ley N²6.727) o mejor conocida como "Estatuto del Peón Rural". Entre otras cuestiones, esta ley establece que la remuneración no podrán ser inferiores al salario mínimo vital y móvil vigente; la vivienda que se provea al trabajador deberá ser sólida, construida con materiales adecuados que garanticen un adecuado estándar de confort y habitabilidad; la alimentación deberá ser sana, suficiente, adecuada y variada; mientras que los vehículos que se utilicen para el traslado de los trabajadores rurales deberán haber sido construidos para el transporte de personas; con respecto al trabajo agrario éste deberá realizarse en adecuadas condiciones de higiene y seguridad a fin de evitar enfermedades profesionales o accidentes de trabajo. Finalmente, esta ley también prohíbe el trabajo de las personas menores de dieciséis años en todas sus formas, exista o no relación de empleo, y sea aquél remunerado o no.

La Ley N ${ }^{\circ} 26.737$ "Régimen de Protección al Dominio Nacional sobre la Propiedad, Posesión o Tenencia de las Tierras Rurales" que fue promulgada en 2011 tiene como principal objetivo regular, respecto de las personas físicas y jurídicas extranjeras, los límites a la titularidad y posesión de tierras rurales, cualquiera sea su destino de uso o producción. Entre otras disposiciones, establece el 15\% como límite a toda titularidad de dominio o posesión de tierras rurales en el territorio nacional a extranjeros. Ese porcentaje se computará también sobre el territorio de la provincia, municipio o entidad administrativa equivalente en que esté situado el inmueble rural. En ningún caso las personas físicas o jurídicas, de una misma nacionalidad extranjera, podrán superar el treinta por ciento $(30 \%)$ de ese porcentual asignado. Las tierras rurales de un mismo titular extranjero no podrán superar las mil hectáreas (1000 ha) en la zona núcleo de producción, o superficie equivalente, según la ubicación territorial.

En la Ley de Reparación histórica de la agricultura familiar para la construcción de una nueva ruralidad en la Argentina (Ley N ${ }^{\circ} 27.118$ ) del 2014 se declara de interés público la agricultura familiar, campesina e indígena por su contribución a la seguridad y soberanía alimentaria del pueblo, por prac- 
ticar y promover sistemas de vida y de producción que preservan la biodiversidad y procesos sostenibles de transformación productiva.

En esta normativa se establece la creación de un Régimen de Reparación Histórica de la Agricultura Familiar destinado al agricultor y a la agricultura familiar y empresas familiares que desarrollen actividad agropecuaria en el medio rural con la finalidad prioritaria de incrementar la productividad, seguridad y soberanía alimentaria y de valorizar y proteger al sujeto esencial de un sistema productivo ligado a la radicación de la familia en el ámbito rural, sobre la base de la sostenibilidad medioambiental, social y económica. De igual manera establece la articulación entre el Poder Ejecutivo nacional y las provincias para favorecer el acceso a la tierra, considerada ésta como un bien social, destinada a la agricultura familiar.

Finalmente resulta insoslayable no aludir al conflicto suscitado entre las patronales agropecuarias y el Gobierno nacional a raíz del aumento de las retenciones en el año $2008^{6}$ es que tal conflicto, como señala Javier Balsa (2013), reinsertó en la agenda pública un debate ausente por largo tiempo en Argentina como lo es la cuestión agraria:

(...) fue recién en la coyuntura del conflicto que emergió a los debates públicos, y se promovió, de modo más colateral que directo, la discusión sobre el modelo de desarrollo agrario deseable para un país democrático. Así, se discutieron formas de segmentación de las retenciones según el tamaño de las explotaciones agropecuarias, un proyecto de ley de arrendamientos que frenara el proceso de concentración y, entre otras cuestiones, los derechos de las familias productoras, los campesinos y los pueblos originarios al acceso a la tierra. (Balsa, 2013, pp. 374-375)

Habida cuenta de que una de las primeras medidas del Gobierno de Mauricio Macri fue la reducción de las retenciones a las exportaciones agrícolas en 5\% para soja y eliminación para maíz, trigo, carnes, nos permitimos al menos preguntarnos si el debate en torno a la apropiación de la renta agrícola no constituye en sí mismo algo más que una variación cuantitativa de ren-

6 Las patronales agropecuarias reacias a un esquema de movilidad en el porcentaje de la alícuota de las retenciones a la exportación de commodities impulsadas por el Gobierno nacional desarrollaron un lockout patronal de aproximadamente cuatro meses para impedir su aprobación. Durante ese período instituciones como la Sociedad Rural Argentina, Confederaciones Rurales Argentinas, CONINAGRO y Federación Agraria Argentina realizaron diversas acciones de protesta para impedir la implementación de la resolución. 
tabilidades al interior del agronegocio o si, en cambio, la apropiación estatal no implica una tensión constitutiva respecto a la lógica agrícola en cuestión, máxime cuando la que lo define a la actual lógica agropecuaria es el "negocio" (apropiación privada mediante) por sobre la producción de alimentos.

A partir de la asunción de la Alianza Cambiemos, algunas leyes y políticas públicas impulsadas durante el Gobierno kirchnerista se vieron modificadas. Un caso es el de la Ley 26.727 de Trabajo Agrario. En noviembre del 2015, apenas tres días después de la elección presidencial, la Corte Suprema de Justicia falló a favor de una presentación realizada años antes por la UATRE (Unión Argentina de Trabajadores Rurales y Estibadores), liderada por Gerónimo "Momo" Venegas, que bregaba por la anulación de dos artículos de la nueva ley que implicaba la creación del organismo estatal RENATEA (Registro Nacional de Trabajadores y Empleadores Agrarios) y la liquidación del ente de derecho público no estatal RENATRE (Registro Nacional de Trabajadores Rurales y Empleadores); y el pase de funciones, patrimonio y personal del segundo al primero.

Tras la disolución del RENATEA, el Gobierno restableció el viejo Registro Nacional de Trabajadores Rurales y Empleadores (RENATRE), para que éste vuelva a funcionar a partir del 1 de enero de 2017. Ante esto a fines de 2016 fueron despedidos 800 empleados en el RENATEA. De esta manera se deja en evidencia el retroceso de los derechos de los trabajadores rurales.

En 2016, con el pretexto de "destrabar las inversiones de afuera" el Gobierno flexibilizó la adquisición de tierras por parte de extranjeros. A través del decreto 820/2016, definió que se considera titular extranjero a quien sea titular de "más del $51 \%$ del capital social de una persona jurídica". Esto cambia la norma que estaba vigente, en la que se definía como extranjero a quien sea titular de "un porcentaje superior al veinticinco por ciento (25\%)"?

Como dijimos anteriormente, en el 2014, se creó la Secretaría de Agricultura Familiar dependiente del Ministerio de Agricultura, de la cual dependían las Subsecretarías de Ejecución de Programas para la Agricultura Familiar y la de Fortalecimiento Institucional. En 2017, mediante el decreto 302/17, el presidente se planteó una redefinición del organigrama del Ministerio de Agroindustria en el que se oficializaba la eliminación de la antigua Secretaría de Agricultura Familiar que pasa a fusionarse con la de Coordinación y Desarrollo Territorial y, de hecho, tiende a desaparecer.

7 Fuente: https://bit.ly/2LRUTSU (10/10/2018). 
Finalmente, bajo el gobierno de Mauricio Macri ha recobrado fuerza el proyecto por la aprobación de una nueva ley de semillas tendiente a favorecer los intereses de las grandes compañías que concentran la producción y comercialización de semillas a nivel mundial; esto en desmedro de las formas ancestrales de agricultura en las que las semillas constituyen un bien común por ende no sujeto a privatización. En tal sentido, recientemente en el marco del Primer Foro Agrario Nacional ( 7 y 8 mayo de 2019) centenares de campesinos y pequeños productores cuestionaron el avance del agronegocio y propusieron a la agroecología como alternativa superadora vis a vis el impulso de una reforma agraria integral.

Esto último da cuenta de que el despliegue del agronegocio no está exento de conflictos y resistencias por parte de diversos colectivos que se enfrentan a las decisiones políticas que profundizan los mecanismos de despojo.

\section{Agronegocio en Brasil. De Lula a Temer}

A grandes rasgos, podríamos decir que las características generales del agronegocio en Brasil guardan marcadas similitudes con lo que sucede en Argentina. Como dijimos anteriormente, Brasil es uno de los países productores agrícolas más importantes del mundo además de ser el país con mayor superficie de América Latina, ocupa aproximadamente 8516 millones de $\mathrm{km}^{2}$.

Según el Censo Agropecuario realizado en el 2006, de esa superficie total 330 millones de hectáreas fueron empleadas por el sector agropecuario durante el periodo 1996-2006.

En la década de 1990 acontecen dos importantes conflictos sociales (Corumbiara, Rondônia, en agosto de 1995 y Eldorado de Carajás, Pará, en abril de 1996) que, al decir de Lauro Mattei (2018), hicieron que la cuestión agraria se apodere de la agenda política nacional a finales del siglo XX. A partir de ello es que el entonces presidente Felipe Cardozo, crea el Ministerio del Desarrollo Agrario (MDA) para atender las necesidades del sector. Pero es recién a partir del gobierno de Luis Ignacio "Lula" Da Silva (Partido de los Trabajadores) que tal cartera implementará políticas de alcance real a los fines de intentar modificar la estructura agraria del país.

Durante el Gobierno de Lula (2003-2010) “ocurrió el mayor número de asentamiento de trabajadores rurales, representando el 52\% del total históricamente realizado en el país" (Mattei, 2018, p. 296) respondiendo a las de- 
mandas de organizaciones y movimientos sociales respecto a la necesidad de democratizar el acceso a la tierra.

Algunos de los programas de mayor envergadura bajo la gestión gubernamental del Partido de los Trabajadores en lo que atañe a las atribuciones del Ministerio de Desarrollo Agrario lo fueron los programas de: Documentación de la Trabajadora Rural (2004); Organización Productiva de Mujeres Rurales (2008); Reordenamiento Agrario y del Crédito Fundiario (2003); adquisición de Alimentos (2003); seguridad Alimentaria y Nutricional (2003).

Aún en el marco de una notable expansión del agronegocio durante la primera década del siglo XXI, los programas referidos, enmarcados en II Plan Nacional de Reforma Agraria (PRNA), significaron un cualitativo y cuantitativo aporte a un tipo de agricultura que dotaba al campo brasileño de mayor sostenibilidad, de incentivo a la agricultura familiar y a la producción agroecológica.

Por su parte durante el Gobierno de Dilma Rousseff (2011-2015) si bien es posible destacar, tal como lo señala Miguel Altieri, la importancia de la creación de la Política Nacional de Agroecología y Producción Orgánica. ${ }^{8}$ Lo cierto es que hubo una desaceleración del número de familias asentadas, reduciéndose drásticamente la distribución de tierras para la reforma agraria: "(...) a lo largo de su gestión fueron asentadas en promedio aproximadamente 25000 familias por año, respecto a una media de 76700 familias por año durante las dos administraciones anteriores de Lula (2003-2010)" (Guereña, 2016, p. 13).

Este fenómeno, sin embargo, no puede ser interpretado cabalmente sino se atiende a un análisis integral con relación al devenir del ejercicio del poder político del PT. Tal como lo hemos analizado en otra oportunidad (Forlani, 2019) efectivamente aconteció un viraje en la política económica del gobierno de Dilma Rousseff pasando de una política heterodoxa inaugurada por "Lula" Da Silva hacia cierta ortodoxia de características neoliberales. Presuponemos que el gobierno de Rousseff consideró que, reiniciando un ciclo de mayor acumulación para el sector privado (vía aumento de las tasas de interés, ajuste fiscal y garantías a la seguridad jurídica), cesarían las

8 Art. $1^{\circ}$ Se establece la Política Nacional de Agroecología y Producción Orgánica-PNAPO, con el objetivo de integrar, articular y adecuar políticas, programas y acciones inductoras de la transición agroecológica y de la producción orgánica y de base agroecológica, contribuyendo para el desarrollo sostenible y la calidad de vida de la población, a través del uso sostenible de los recursos naturales y de la oferta y consumo de alimentos saludables. Fuente: https://bit.ly/1hKM06C 
presiones de los sectores conservadores y, al calor de un incremento en la inversión privada, los trabajadores perjudicados por las políticas de transferencia de recursos serían beneficiados del derrame del crecimiento económico futuro. En otras palabras "las políticas neoliberales llevadas adelante tras el triunfo electoral socavaron las bases de apoyo popular al PT al tiempo que enaltecieron los sectores concentrados del Brasil (...) que divisando la debilidad del gobierno de Rousseff dispusieron finalmente su destitución" (Forlani, 2019, s/n).

Consumado el golpe hacia la legítima presidenta de Brasil, el Gobierno de Michel Temer operó en materia agraria desarticulando el marco institucional que más allá de sus limitaciones objetivas buscaba amparar las lógicas y actores disidentes al modelo del agronegocio. Así lo ilustran la desestructuración del programa de adquisición de alimentos y de las asistencias técnicas y extensión rural (Mattei, 2018).

Entre las consecuencias más importantes podemos observar, por un lado, una profundización de la violencia y, por el otro, una mayor desigualdad: “(...) sólo en el año 2016 fueron asesinadas a 59 personas involucradas en la lucha por la reforma agraria en el país, número que no ocurría desde el año 2003, cuando 71 personas fueron asesinadas" (Mattei, 2018, p. 305, traducción propia).

Asimismo, los sectores históricamente vulnerados del agro brasileño no se encontraron en la agenda prioritaria de las políticas públicas vinculadas al sector. Aún más la política oficial tendió a una mayor profundización de la situación de exclusión de éstos. De hecho, durante los años 2016 y 2017 ninguna nueva familia fue asentada, al tiempo que no se creó ningún proyecto de asentamiento agrario (Mattei, 2018).

La administración durante el intervalo de Temer significó la desestructuración de la órbita institucional estatal tendiente a la reducción de las desigualdades en el agro brasileño. Programas, áreas y cuerpos técnicos de asistencia a pequeñas unidades campesinas $\mathrm{y} / \mathrm{o}$ de pequeños productores fueron vaciadas y desmanteladas, todo ello como consecuencia de una marcada reducción presupuestaria.

Durante los primeros meses de Gobierno de Jair Bolsonaro (asumió el $1^{\circ}$ de enero de 2019) la situación con respecto a la realidad agraria parece expresar más continuidades que rupturas. De hecho, a poco de asumir, el Ministerio de Agricultura recayó en manos de Teresa Cristina da Costa quien presidía la bancada del agronegocio en la cámara de diputados. 
Concomitante con esto uno de los primeros decretos presidenciales estableció el traspaso de las principales actividades ejecutadas por la Fundación Nacional del Indio (FUNAI) al Ministerio de Agricultura, actividades que comprendían la identificación, delimitación y demarcación de tierras indígenas. Esto implicaría que éstas podrían quedar bajo propiedad de los grandes terratenientes en desmedro de los pueblos originarios ampliando la estructural desigualdad que padece este país latinoamericano.

\section{Conclusiones}

En este trabajo realizamos un recorrido por las políticas relacionadas al agronegocio en tanto lógica productiva impulsadas tanto en Brasil como en Argentina. Para ello retomamos las principales medidas implementadas por los gobiernos vinculados a la ola progresista latinoamericana (Néstor y Cristina Kirchner en Argentina y Lula Da Silva y Dilma Rousseff en Brasil) y las comparamos con lo sucedido con esas políticas cuando asumieron en los gobiernos nacionales de ambos países presidentes cuyas posiciones se encuentran a la derecha del espectro político (Mauricio Macri y Michel Temer).

Las políticas públicas de corte neoliberal que impulsan los gobiernos de derecha en Argentina y Brasil potencian y profundizan las desigualdades sociales y económicas en ambos países. Se trata de decisiones que favorecen los intereses de las grandes empresas y terratenientes por sobre campesinos y pequeños productores.

Las políticas de derecha de los países analizados en este trabajo intensifican la matriz extractivista de los proyectos de desarrollo impulsados durante la "década progresista" en ambos países. Sin embargo, a diferencia de lo sucedido en los últimos años, el ingreso que generan las mínimas retenciones impuestas a estas actividades no parece emplearse en programas que favorezcan las lógicas internas de producción y consumo, tampoco para la generación de nuevas fuentes de trabajo o políticas públicas que beneficien a los sectores más vulnerados de la sociedad; todo lo contrario, las medidas adoptadas conllevan a una mayor ampliación de la brecha de desigualdad en ambos países. 


\section{Bibliografía}

Amin, S. (2005). Más allá del capitalismo senil. Por un siglo XXI no norteamericano. Buenos Aires: Paidós.

Balsa, J. (2013). Modelos agrarios en disputa y el posicionamiento del kirchnerismo. En J. Balsa (Comp.), Discurso, política y acumulación en el kirchnerismo. Buenos Aires: Ed. Pensamiento Crítico.

Basualdo, F., Barrera, M. \& Basualdo, E (2013). Las producciones primarias en la Argentina reciente. Minería y petróleo. Buenos Aires: Ed Atuel.

Bobbio, N. (1995). Derecha e izquierda. Razones y significados de una distinción política. Madrid: Taurus.

García Linera, A. (2016). ¿Fin de ciclo progresista o proceso por oleadas revolucionarias? En E. Sader (Coord.), Las vías abiertas de América Latina. Buenos Aires: Octubre.

Giarracca, N., \& Teubal, M. (2013). Las actividades extractivas en la Argentina. En N. Giarracca y M. Teubal (Coords.), Actividades extractivas en expansión ¿Reprimarización de la economía argentina? Buenos Aires: Editorial Antropofagia.

Gras, C., \& Hernández, V. (2013). El agro como negocio. Buenos Aires: Biblos.

Giordano, V. (2014). ¿Qué hay de nuevo en las 'nuevas derechas'? Nueva Sociedad, 254, 46-56.

Guereña, A. (2016). Desterrados: tierra, poder y desigualdad en América Latina. Informe de OXFAM. Recuperado de: https://bit.ly/2YyxtEb

Forlani, N. (2019). Claves interpretativas del golpe en Brasil. Revista Interdisciplinaria Estudios Sociales, 18 (en prensa).

Frederico, S., \& Gras, C. (2017). Globalização financeira e land grabbing: constituição e translatinização das megaempresas argentinas. En J. Bernardes, S. Frederico, C. Gras, V. Hernández, y G. Maldonado (Orgs). Globalização do agronegócio e Land grabbing. A atuação das megaempresas argentinas no Brasil. Río de Janeiro: Editorial Lamparina.

Harvey, D. (2005). El "nuevo” imperialismo: acumulación por desposesión. Socialist Register 2004. Recuperado de: https://bit.ly/1TPbNiF

López Segrera, F. (2016). América Latina: crisis del posneoliberalismo y ascenso de la nueva derecha. Buenos Aires: CLACSO.

Maldonado, G. (2013) El agro en la urbe. Expresión del circuito superior de la producción agropecuaria en la ciudad de Buenos Aires (Argentina). Re- 
vista Scripta Nova. Revista electrónica de geografía y ciencias sociales, 17(452). Recuperado de: https://bit.ly/2ytbP9v

Martínez Dougnac, G. (2013). Lógica y tendencias de un modelo agrario que persiste. En J. Balsa (Comp.), Discurso, política y acumulación en el kirchnerismo. Buenos Aires: Ed. Pensamiento Crítico.

Mattei, L. (2018) A política agrária e os retrocessos do governo Temer. OKARA: Geografia em debate, 12(2), 293-307. Recuperado de: https://bit. ly/2SWzbOk

Natanson, J. (2017). Cuando la desigualdad es una elección popular. Le monde diplomatique 217, 1-3. Recuperado de: https://bit.ly/2KtKSsb

Quiroga, M. V., \& Juncos Castillo, L. (2018). Derechas y políticas sociales: ¿el encuentro (im)posible? Un análisis sobre los actuales gobiernos de Argentina y Brasil. 8va. Conferencia Latinoamericana y Caribeña de Ciencias Sociales, organizada por CLACSO. Buenos Aires, 22 y 23 de noviembre de 2018. Inédito.

Sader, E. (2015). ¿Hay una nueva derecha en América Latina? Página 12, 24/11/2015. Recuperado de: https://bit.ly/2Mt5mnd

\section{Fuentes}

Ley $\mathrm{N}^{\circ} 26.331$ Presupuestos mínimos de protección ambiental de los bosques nativos. Boletín Oficial de la República Argentina, Buenos Aires, Argentina, 26 de diciembre de 2007.

Ley N²6.727 Régimen de Trabajo Agrario. Boletín Oficial de la República Argentina, Buenos Aires, Argentina, 28 de diciembre de 2011.

Ley N²6.737 Régimen de Protección al Dominio Nacional sobre la Propiedad, Posesión o Tenencia de las Tierras Rurales. Boletín Oficial de la República Argentina, Buenos Aires, Argentina, 28 de diciembre de 2011.

Ley N²7.118 Reparación Histórica de la Agricultura Familiar para la Construcción de una Nueva Ruralidad en la Argentina. Boletín Oficial de la República Argentina, Buenos Aires, Argentina, 28 de enero de 2015.

Fecha de envío: 2019/05/25; Fecha de aceptación: 2019/07/23;

Fecha de publicación: 2019/09/01 